\title{
LITERATURA, MÚSICA FLAMENCA Y ARTES ESCÉNICAS: COMPARATISMO INTERDISCIPLINAR Y TRADUCCIÓN DE CÓDIGOS
}

\author{
Literature, Flamenco Music and Performing Arts: \\ Interdisciplinary Comparatism and Translation of Codes
}

Francisco Javier Escobar Borrego

Universidad de Sevilla

fescobar@us.es

Emilio J. GALLARDO-SABORIDO

Escuela de Estudios Hispano-Americanos, CSIC

emilio.gallardo@csic.es

Recibido: 28/10/2019; Aceptado: 07/05/2020; Publicado: 31/12/2021

Ref. Bibl. FRANCISCO JAVIER ESCOBAR BORREGO Y EMILIO J. GALLARDO-

SABORIDO. LITERATURA, MÚSICA FLAMENCA Y ARTES ESCÉNICAS:

COMPARATISMO INTERDISCIPLINAR Y TRADUCCIÓN DE CÓDIGOS. 1616:

Anuario de Literatura Comparada, 11 (2021), 9-16.

RESUMEN: En los estudios especializados en flamenco, sobresale, por su presencia y notoriedad, una línea de investigación circunscrita a la traducción e intersección de códigos estéticos entre literatura, música y artes escénicas. En este sentido, el análisis técnico a la luz del comparatismo interdisciplinar resulta un vehículo metodológico óptimo para comprender las múltiples aristas que tan complejo objeto de estudio poliédrico y reticular atesora. Por tales razones, los avances y aportes epistemológicos y gnoseológicos que se ofrecen en el presente monográfico, respecto al estado de la cuestión, arrojan luz, en fin, sobre nuevos caminos y senderos no hollados a efectos de perspectivas críticas. 
FRANCISCO JAVIER ESCOBAR BORREGO Y EMILIO J. GALLARDO-SABORIDO LITERATURA, MÚSICA FLAMENCA Y ARTES ESCÉNICAS: COMPARATISMO INTERDISCIPLINAR...

Palabras clave: Música; Artes escénicas; Performatividad; Flamenco; Literatura comparada; Comparatismo interdisciplinar.

ABSTRACT: In specialized studies on Flamenco, a line of research circumscribed to the translation and intersection of aesthetic codes between literature, music and performing arts stands out due to its presence and notoriety. In this sense, technical analysis in the light of interdisciplinary comparison is an optimal methodological vehicle to understand the multiple edges that such a complex, multifaceted and reticular object of study treasures. For these reasons, the advances and epistemological and gnoseological contributions that are offered in this special issue, regarding the state of the art, shed light, in short, on new paths and untrodden paths for the purposes of critical perspectives.

Keywords: Music; Performing Arts; Performativity; Flamenco; Comparative Literature: Interdisciplinary Comparatism.

En el estado de la cuestión circunscrito a la intersección de códigos entre flamenco y literatura en la Edad Contemporánea, se hace necesaria la propuesta de nuevas metodologías de investigación, enfoques epistemológicos-gnoseológicos y categorías conceptuales que atañen al comparatismo entre las artes. El presente monográfico ofrece, de hecho, una granada selección de estudios inéditos y coordinados entre sí, como si de un mosaico poliédrico se tratase, a partir de las relaciones fronterizas y de diálogo interdisciplinar entre literatura, música, danza y pintura, en el que no falta tampoco la performatividad o acto performativo.

Así pues, consideramos el flamenco como un lenguaje de estética creativa que, más allá de la evidencia musical, atesora la potencialidad de impregnar conceptualmente al resto de las artes, posibilitando fructíferos diálogos estéticos de naturaleza múltiple. Esta rica complejidad del flamenco ha sido testimoniada, en efecto, en distintas empresas académicas acometidas en los últimos años desde la Universidad de Sevilla y la Universidad de Cádiz, y que han favorecido la reunión intelectual de los autores presentes en este monográfico.

En concreto, se hace oportuno y necesario evocar laboriosos empeños como el programa de doctorado de la Universidad de Sevilla «El Flamenco. Acercamiento multidisciplinar a su estudion, desde el curso 2004-2005, y "Estudios avanzados de flamenco: un análisis interdisciplinar", desde 2009 (Pablo 2012, 43). Este programa, que concluyó finalmente en 2017, vino a atestiguar un certero entendimiento del flamenco como fenómeno plurifacético en lo que a su economía creativa se refiere, de modo que en él colaboraron: «[...] antropólogos, sociólogos, psicólogos, historiadores, musicólogos, folcloristas, sociolingüistas, filólogos y matemáticos, entre otros» 
(Pablo 2012, 43). Más recientemente, la Universidad de Cádiz ha tomado este testigo y legado docente-investigador consagrado al flamenco y, desde el curso académico 2018-2019, organiza el Máster Interuniversitario en Investigación y Análisis del Flamenco, que goza actualmente de una excelente vitalidad, proporcionada, entre otros factores, por la considerable demanda que ha suscitado entre un alumnado de alta cualificación profesional y de procedencia diversa.

Por último, la Editorial de la Universidad de Sevilla (EUS) ha impulsado recientemente una novedosa colección temática, bajo la codirección de Francisco J. Escobar y Rocío Plaza Orellana, dedicada a estudios monográficos que tienen como objeto de análisis medular el flamenco. Fruto de ello ha resultado la forja de los volúmenes Negro sobre blanco. Investigación, patrimonio, cine y neoflamenco (Cruces Roldán 2017), Estética de lo jondo. Poesía y pintura de Francisco Moreno Galván (Martín Cabeza 2018), Flamenco y canción española (Luna López 2019), Los cantes de laboreo de Torredelcampo (Alcántara Moral 2019), Para cantar flamenco bay que ponerse fea (Pantoja 2019) y El flamenco. Baile, música y lírica: Precedentes histórico-culturales y primer desarrollo (1780-1880), en coedición con el Servicio de Publicaciones de la Universidad de Granada (ed. Berlanga 2021). En tales obras se reconoce, en suma, un denominador común gracias al enfoque comparatista interdisciplinar implementado desde un prisma investigador poliédrico. Como señalan Francisco J. Escobar y la reconocida cantaora Carmen Linares en el texto preliminar como pórtico de entrada a Los cantes de laboreo de Torredelcampo:

Dicho paradigma estilístico para estos cantes a cappella de Torredelcampo en calidad de poligénesis, o sea entre la tradición popular oral y la rúbrica de autor (sfragis), pone de relieve la necesidad, cada vez más imperiosa, de implementar en dicho objeto de estudio poliédrico los planteamientos metodológicos, las categorías conceptuales-epistemológicas, así como las herramientas e instrumentos de análisis de la etnomusicología y otras disciplinas auxiliares afines al trasluz de una cooperación o acción colegiada interdisciplinar. Así ha procedido el autor de este volumen en el que no han faltado ni la intersección de códigos entre literatura, música y otras artes, en una armonización de enfoques diacrónicos y sincrónicos, como tampoco las sutiles modulaciones hacia variadas perspectivas críticometodológicas, tales como los estudios de género desde el postestructuralismo hasta los Estudios Culturales. [...]

Por tanto, se podrán recordar a este respecto [...] nombres tan destacados como los de Zoltán Kodály, Béla Bartók, Carl Stumpf, Vinko Zganec, Franjo Kuhar, Erich von Hornbostel, Komitas, Hugh Tracey o Constantin Brăiloiu, pasando por los de Curt Sachs, Alexander J. Ellis, Manuel de Falla o Federico García Lorca, con romances, canciones, nanas, jaleos y otras formas genéricas similares al fondo, tan importantes en la forja, transmisión y recepción del flamenco contemporáneo, hasta llegar, ya 
FRANCISCO JAVIER ESCOBAR BORREGO Y EMILIO J. GALLARDO-SABORIDO

LITERATURA, MÚSICA FLAMENCA Y ARTES ESCÉNICAS: COMPARATISMO INTERDISCIPLINAR...

como sólidos cimientos de la etnomusicología y la estética comparada actuales, a John Blacking, Bruno Nettl, Alan P. Merriam, Mantle Hood, Theodor Adorno, Helen Myers, Ruth Stone, Jean-Jacques Nattiez, Ramón Pelinski o Alan Lomax, entre otros conocidos nombres. Todos ellos, en cualquier caso, sea desde los postulados teóricos o bien de la misma práctica compositiva, o ambos campos a su vez en una rica interacción a modo de simbiosis, retroalimentación o feedback [...], atendieron y se entregaron de pleno a una consciente labor de campo en la que, a modo de bajo continuo u ostinato, se erigían como piezas cruciales las voces y perfiles de los informantes en calidad de valiosas fuentes de transmisión oral en aras del rescate de un patrimonio inmaterial que venía a atesorar un notorio y manifiesto valor, más allá de entrevistas dirigidas o semidirigidas, cualitativas o cuantitativas como técnicas y herramientas de trabajo. (Escobar y Linares 2019, 14-15)

Como se ve, la perspectiva comparatista interdisciplinar no resulta solamente oportuna, sino que se muestra imprescindible para poder comprender de manera cabal y rigurosa la complejidad sociocultural de lo flamenco. Ahora bien, aunque no nos ocupa ahora la tarea de llevar a cabo una exhaustiva revisión de este diálogo interartístico, no resulta una cuestión baladí subrayar que el mismo se remonta a los connaturales e intrínsecos orígenes del flamenco habida cuenta de que se rastrea fácilmente en la pintura y la literatura costumbristas; en las prácticas escénicas que tomaron a lo largo del siglo XIX salones y cafés cantantes, entre otros representativos marcos escénicos, al tiempo que se desplegaron y expandieron posteriormente por teatros de toda la geografía peninsular, así como por toda suerte de espacios escénicos; por ejemplo, en amistades y admiraciones mutuas como la del poeta y pintor Rafael Alberti y el cantaor José Menese (Bernal 2018, 117-118); en la fascinación fúlmica permanente desde, prácticamente, la irrupción de este nuevo arte (Cruces Roldán 2017) con especial énfasis en directores tan señeros como Carlos Saura; y en una miríada de casos, motivos y encuentros más. Valgan, en calidad de broche final, las conocidas estampas poéticas que Federico García Lorca consagró a tres figuras señeras del arte flamenco en sus «Viñetas flamencas» integradas en Poema del cante jondo (1931), donde eleva, a nivel de écfrasis poético-musical, a artistas del calado de Silverio Franconetti, Juan Breva y la Parrala. Concluyamos, en fin, que la proyección multiartística se inserta en la masa de la sangre de lo flamenco.

A la vista de lo expuesto en el marco contextual precedente, específicamente, para esta propuesta monográfica, acotada desde la literatura romántica $c a$. 1820, pasando por el modernismo y mediados del siglo xx, hasta culminar en las últimas tendencias contemporáneas, se ha seleccionado a reconocidos investigadores, vinculados a centros universitarios y de investigación de España, Francia y Alemania, que vienen aportando hasta la fecha una sólida, además de novedosa, investigación al respecto. 
Pues bien, desde este prisma interdisciplinar, el presente ramillete o gavilla de estudios se abre con la aportación de Rocío Plaza Orellana bajo el título "Carmen y el color local de España: orientalismo, gitanos y bailes". En dicho trabajo, se presta especial atención a la caracterización o naturaleza genérica de la conocida ópera Carmen, de Georges Bizet, con libreto de Prosper Mérimée, a partir del paulatino proceso evolutivo de tres de sus rasgos escénicos más significativos, esto es: el orientalismo, la etnia gitana y la danza española. Especial interés merece su examen crítico del libreto, sobre todo en lo que hace a sus acotaciones y los signa escenográficos más notables en entronque con la práctica escénica identificable en París desde la segunda década del siglo XIX.

En efecto, el aire bohemio y decadente reconocible en la tradición romántica y modernista, con raigambre y filiación estética francesa, viene a auspiciar sentimientos y emociones por parte del individuo en su visión intimista de lo popular que van a configurar su propio sentido de subjetividad, según vino a apuntar ya Antonio Machado y Álvarez, Demófilo. Sobre este particular, Antonio Plaza Orellana, en «... Como si el poeta no perteneciese al pueblo: los cantares de Ruiz Aguilera en el repertorio flamenco", propone un análisis a partir de la denominada poesía de cantares y su vinculación simbólico-cultural con el flamenco. Para ello, pone especial énfasis en la proyección que en esta estética musical tan definida y plural ha tenido la producción poética del salmantino Ventura Ruiz Aguilera. Su enfoque, en definitiva, permite a los lectores adentrarse en cuestiones axiales, en lo que concierne a la génesis, forja y desarrollo del corpus de la lírica flamenca, tales como la noción conceptual de autoría o las mixturas y lábiles trasvases fronterizos entre poesía culta y popular. Del mismo modo, sobresalen perspectivas nucleares planteadas como la técnica mimética reconocible en el cantar popular y sus implicaciones referidas al compromiso social y otras actitudes vitales, sentimentales y emocionales arraigadas en el imaginario colectivo. Se trata, en fin, de un contexto literario y cultural en el que no están ausentes, claro está, las soledades, con Augusto Ferrán y Machado y Álvarez en calidad de figuras principales.

Tanto es así que, en las fronteras entre los cantares del pueblo, los cantes flamencos y la canción española, acabará teniendo lugar, como arte de la memoria, la forja y génesis de una modalidad genérica híbrida y fronteriza circunscrita temáticamente en la soledad, como analiza con de-

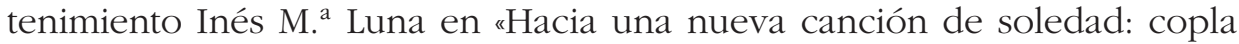
flamenca y canción española». Y es que, como fruto del nacimiento de este género, la copla andaluza se acabó transformando en una canción de soledad con puntos de encuentro respecto a la concepción espiritual de la copla flamenca. De hecho, desde esta aportación crítica, cobra pleno sentido el desarrollo evolutivo del cuplé en una andadura en el tiempo desde 
las décadas de los años veinte y treinta del siglo xx, con notoria relevancia de luminarias como Rafael de León, hasta la actualidad.

Estamos, como se ve, ante la continua y dilatada presencia de discursos híbridos que, al implicar una compleja intersección de códigos entre el discurso poético y el musical, requieren necesariamente un estudio minucioso y riguroso desde el comparatismo estético. Ahora bien, un excelente conocedor de tales hibridaciones entre los géneros y las artes, incluyendo la narratividad en verso y prosa, en el ámbito hispánico fue el pintor y escritor Francisco Moreno Galván. Se erige, en síntesis, como una de las figuras más destacadas y singulares para el conocimiento cabal de la paulatina evolución del flamenco en la Edad Contemporánea, habida cuenta de que se propuso armonizar a la perfección el conocimiento de la tradición del flamenco con las más avanzadas tendencias artísticas vanguardistas. A este respecto, Juan Diego Martín Cabeza, en «Francisco Moreno Galván, autor de letras flamencas», traza un análisis ceñido a la deuda de este creador con la copla o letra flamenca de sabor popular, con la atinada identificación de fuentes a partir de Demófilo, Antonio y Manuel Machado, y la tradición lírica en castellano, con resonancias de Lope de Vega, Francisco de Quevedo y otros ingenios de las letras de la Edad de Oro. Asimismo, dicho investigador pone de relieve las características y rasgos de la propia originalidad conceptual de Moreno Galván, como deja ver la creación de letras flamencas para las voces de José Menese, Miguel Vargas o Diego Clavel, entre otras distinguidas figuras del flamenco contemporáneo.

Asistimos, por tanto, en el caso de Moreno Galván, a una armónica conjugación de letras flamencas individualizadas y redactadas para que cobren corporeidad performativa en la práctica escénica, pero también que conforman de manera integral ciclos temáticos, por lo general con un sentido ético y significado cívicos orientados hacia la denuncia de injusticias y sinsabores de la vida en aras de abogar por un mundo presidido por valores humanos. Como se trasluce en el usus scribendi de Moreno Galván y otros autores polifacéticos y versátiles, las coplas flamencas pueden atesorar sentido per se como unidades aisladas, con una función fragmentaria, es verdad, si bien suele suceder que el conjunto unitario, coherente y cohesionador de un elenco de letras por parte de un cantaor o cantaora hace que estas coplas adquieran nuevos sentidos y contextos, siempre renovados desde la práctica escénica.

Por esta razón, Florian Homann, en "Coplas flamencas sueltas y poemas del cante compuesto: dos moldes distintos de las letras del cante, entre textos tradicionales y textos de nueva creación", se decanta por el deslinde conceptual entre copla flamenca y poema del cante (compuesto) con el propósito de llevar a cabo un análisis al calor de un selecto corpus contextualizado en la Edad Contemporánea. Este estudio arroja luz, por tanto, sobre el papel desempeñado por los cantaores en calidad de antólogos, 
por la cuidada selección de letras, e incluso, en ocasiones, coautores del macrotexto generado debido a un proceso de reajustes y adaptación que implica una reescritura, a modo de palimpsesto, o palingénesis en virtud de un proceso de intertextualidad que conlleva hasta un cambio de significado literario durante la repentización in fieri. Así, el cantaor o cantaora decide adaptar la copla transmitida como arte de la memoria a su universo subjetivo, personal e intransferible, que actualiza estéticamente en el hinc et nunc del contexto escénico.

Sin embargo, en otras ocasiones, más allá del texto cantado, puede primar más bien el contexto y espacio escénico en virtud de práctica performativa. Sucede especialmente en la escenificación o teatro musical aplicado a un espectáculo de raigambre flamenca, pero que integra, a su vez, otros lenguajes y códigos plurales. Este es el caso paradigmático de la poética teatral del coreógrafo Andrés Marín, quien, en espectáculos del calado y fuste de Golgota (2013), viene a explorar complejos caminos de experimentación, a efectos de teatro (o danza) ecuestre-musical, tras transitar modulaciones por el cabaret y la ópera ecuestre, al margen de géneros definidos y modalidades estilísticas concretas del flamenco tradicional y canónico.

Como analiza Corinne Frayssinet Savy en "Golgota: réévaluation d'un genre, le théâtre équestre", al trasluz de planteamientos conceptuales de Roland Barthes, Frédéric Pouillaude o Pascal Jacob, desde su «filosofía de la danza", Bartabas y Marín invitan a los espectadores-lectores a adentrarse en una sugerente experiencia sensorial y sensitiva con citas y guiños a diferentes discursos como el pasionista polifónico de Tomás Luis de Victoria, en un verdadero maridaje de sonido y silencio como página en blanco. Para ello, llega a confluir con la ritualidad de una saeta primitiva al tiempo que da paso a otros estilos genéricos de relieve como seguiriyas, martinetes y bulerías. De hecho, su propuesta, visiblemente orgánica a nivel de arquitectura conceptual y como reescritura de los códigos ortodoxos del flamenco, está vinculada a lo que se viene denominando sinestesia multidireccional en un espacio ritual y cultual. Por lo demás, Marín procede desde este modus operandi creativo con el objeto de realizar una crítica transgresora y paródica, con ironía y notas que rozan lo grotesco de fondo, de tópicos imperantes en la sociedad, que tienen referentes concretos en Andalucía, incluyendo la práctica antigua de los empalaos.

Reescrituras simbólicas y transgresoras al margen, como podrán comprobar los lectores del presente volumen, el eje vertebrador brindado en estas páginas resulta medular, en esta segunda década del siglo XXI, en lo que atañe a la investigación consagrada al flamenco como riguroso objeto de estudio; y lo es tanto a efectos de una certera revisión crítica del estado de la cuestión, tan necesaria todavía, como para el acceso granado y útil a una propuesta actualizada de perspectivas analíticas al servicio de futuras investigaciones interdisciplinares, como aquellas reseñadas en 
FRANCISCO JAVIER ESCOBAR BORREGO Y EMILIO J. GALLARDO-SABORIDO

LITERATURA, MÚSICA FLAMENCA Y ARTES ESCÉNICAS: COMPARATISMO INTERDISCIPLINAR...

el cierre de este monográfico. Firmadas por Guillermo Castro y Emilio J. Gallardo-Saborido, estas revisiones de los volúmenes Los cantes de laboreo de Torredelcampo (Antonio Alcántara, 2019) y Pregones flamencos. El cante de los vendedores ambulantes andaluces (Rafael Cáceres Feria y Alberto del Campo Tejedor, 2020) testimonian cómo, en las nuevas contribuciones a los estudios flamencos, es habitual encontrar un armónico ensamble entre las perspectivas literarias, musicológicas, antropológicas e históricas, demostrando, una vez más, la necesaria naturaleza interdisciplinar de este fértil campo de estudio.

\section{BiBLIOGRAFÍA}

Alcántara Moral, Antonio. Los cantes de laboreo de Torredelcampo. Sevilla: Editorial de la Universidad de Sevilla. Colección Flamenco, 2019.

Berlanga, Miguel Á. (ed.). El flamenco. Baile, música y lírica: Precedentes histórico-culturales y primer desarrollo (1780-1880). Granada y Sevilla: Editoriales Universidad de Granada y Universidad de Sevilla. Colecciones Patrimonio Musical y Flamenco, 2021.

Bernal Romero, Manuel. El flamenco y la generación del 27. Sevilla: Renacimiento, 2018.

Cruces Roldán, Cristina. "Presencias flamencas en los archivos Gaumont Pathé. Registros callejeros en la Granada de 1905». En Cruces Roldán, Cristina. Negro sobre blanco. Investigación, patrimonio, cine y neoflamenco. Sevilla: Editorial de la Universidad de Sevilla e Instituto Andaluz del Flamenco. Colección Flamenco, 2017, pp. 27-53.

ESCOBAR, Francisco J. y Carmen LINARES. «Sembrar en buena tierra: la etnomusicología como método de análisis interdisciplinar». En AlCÁNTARA MORAL, Antonio. Los cantes de laboreo de Torredelcampo. Sevilla: Editorial de la Universidad de Sevilla. Colección Flamenco, 2019, pp. 12-17.

LUNA LÓPEZ, Inés. Flamenco y canción española. Sevilla: Editorial de la Universidad de Sevilla. Colección Flamenco, 2019.

Martín Cabeza, Juan Diego. Estética de lo jondo. Poesía y pintura de Francisco Moreno Galván. Sevilla: Editorial de la Universidad de Sevilla. Colección Flamenco, 2018.

PABlo LozANO, Eulalia. "Programa Interdepartamental de Doctorado "El flamenco. Acercamiento multidisciplinar a su estudio" y "Estudios avanzados de Flamenco: un análisis interdisciplinar". La nueva Alboreá, 2012, 23, pp. 43-45. https://www.juntadeandalucia.es/cultura/flamenco/content/programa-interdepartamental-de-doctorado-el-flamenco-acercamiento-multidisciplinar-su [8 de marzo de 2020].

Pantoja Guerrero, Dolores. Para cantar flamenco hay que ponerse fea: Las claves de comunicación del cante. Sevilla: Editorial de la Universidad de Sevilla. Colección Flamenco, 2019. 